F. Child Lang. 37 (2010), 963. (C) Cambridge University Press 2010 doi:I0.1017/So305000910000310

E R R A T U M

\title{
Computational models of child language learning: an introduction - ERRATUM
}

\section{BRIAN MACWHINNEY}

doi : I o. I I 7/So3050009 I0000 I 39, Published by Cambridge University Press, 25 March 2010

Most unfortunately there was an error in the 3 rd line from the bottom of page 480 of this introduction. We sincerely apologise to Gaja Jarosz for referring to her as 'he'. The correct version should read:

HG (Harmonic Grammar). She states that all three models incorporate the

\section{REFERENCE}

MacWhinney, B. (2010). Computational models of child language learning: an introduction. Fournal of Child Language 37, 477-485. 